\title{
Histopathological Classifications of Oral Leukoplakia and its Relation to Cell Proliferative Activity: A Case Series
}

\author{
Jéssica F de Camargo ${ }^{1}$, Sara de F Ribeiro ${ }^{2}$, Gisele Rovani ${ }^{3}$, Carla Piardi ${ }^{4}$, Valquíria de J Freitas ${ }^{5}$, Diego J Gambin ${ }^{6}$,
} Micheline S Trentin 7 , Maria S Sandini Linden ${ }^{8}$, João P De Carli ${ }^{9}$

\begin{abstract}
Aim: This study relates the average number of nucleolar organizing regions (NORs) obtained in a series of cases of oral leukoplakia, with three methods of histopathological classification of such lesion.

Materials and methods: This is a histopathological-histochemical laboratory cross-sectional study. The 18 cases of leukoplakia analyzed were filed at Pathology Service of the Biological Sciences Institute of the University of Passo Fundo, Rio Grande do Sul, Brazil (SDH/ICB/UPF) (2017 and 2018), from which epidemiological data were extracted. New histological sections were performed for impregnation by the argyrophilic nucleolar organizer regions (AgNOR) technique. The histopathological slides were analyzed by photon microscopy $(1,000 \times)$, and the nuclei of 100 epithelial cells were photographed to count the number of NORs. Three methods were used for the lesions' histopathological classification [World Health Organization (WHO), Brothwell, and binary system]. The means of NORs were compared with the three histopathological classifications by means of the $t$ or analysis of variance (ANOVA) statistical tests, at a significance level of $5 \%$.

Results: According to the WHO classification method, most cases (11-61.1\%) had a moderate classification. Evaluations by the Brothwell method showed moderate and mild classification in 50 and $38.9 \%$ of cases, respectively. According to the binary system, most cases (10-55.6\%) had low risk. The average NORs found in 100 nuclei of each of the 18 lesions ranged from 2 to 4 . When crossing the average NORs with the histopathological classification methods of the lesions by means of the $t$ test or ANOVA, no significant relationship was noted.

Conclusion: The average of NORs is not associated with the histological classifications of leukoplakias. Thus, the AgNOR method should be used with caution when differentiating different histological grades of leukoplakias.

Clinical significance: The AgNOR method should be used with caution to determine the clinical treatment of oral leukoplakias, since no agreement was observed between this method and the histopathological classifications available for such lesion.

Keywords: Argyrophilic nucleolar organizer regions, Diagnosis, Histological classification, Leukoplakia, Prognosis.

The Journal of Contemporary Dental Practice (2020): 10.5005/jp-journals-10024-2840
\end{abstract}

\section{INTRODUCTION}

Epidermoid carcinoma is the most common neoplasm that affects the mouth, representing about $90 \%$ of the malignancies of such anatomical location. ' Clinically, in its premalignant stage, epidermoid carcinomas may present as leukoplakias, erythroplasias, or erythroleukoplasias. ${ }^{2-6}$

The term "leukoplakia" is a clinical name that characterizes the lesion as a predominantly white patch or plaque of the oral mucosa, not scraping removable, and that cannot be clinically classified as any other pathological entity. ${ }^{2}$ It may have a smooth, rough, or warty surface, ${ }^{7}$ occurring mainly in the jugal mucosa and lips, in addition to the alveolar mucosa, tongue, hard palate, soft palate, floor of the mouth, and gingiva. ${ }^{6}$ Histopathological changes in leukoplakia may range from hyperkeratosis and acanthosis to epithelial dysplasia, or even in situ carcinoma or invasive squamous cell carcinoma. ${ }^{2-4,8}$

Worldwide, oral leukoplakia prevalence varies, and it may represent from 11.1 to $48.9 \%$ of cancerous changes. ${ }^{3,9-12}$ It is considered a multifactorial etiopathogenesis lesion, ${ }^{13}$ mainly caused by tobacco and alcohol consumption, over 40 age, poor oral hygiene, poor prostheses fitting, and inadvertent sun exposure. ${ }^{11,12,14}$

Mortality caused by carcinomas correlates with the stage of diagnosis and prevention of cancerous lesions such as oral leukoplakias. ${ }^{2,4,15}$
${ }^{1}$ Department of Cell Biology, Biological Sciences Institute, University of Passo Fundo, Passo Fundo, Rio Grande do Sul, Brazil

${ }^{2-9}$ Department of Oral Medicine, School of Dentistry, University of Passo Fundo, Passo Fundo, Rio Grande do Sul, Brazil

Corresponding Author: João P De Carli, Department of Oral Medicine, School of Dentistry, University of Passo Fundo, Passo Fundo, Rio Grande do Sul, Brazil, Phone: +55-54-3316-8402, e-mail: joaodecarli@upf.br

How to cite this article: de Camargo JF, Ribeiro SF, Rovani G, et al. Histopathological Classifications of Oral Leukoplakia and its Relation to Cell Proliferative Activity: A Case Series. J Contemp Dent Pract 2020;21(6):651-656.

Source of support: The present study was supported by PIBIC/UPF and PIBIC/CNPq Programs

Conflict of interest: None

To determine the degree of leukoplakia epithelial dysplasia, classification criteria were created. The most widely used histopathological classification model was proposed by the WHO and evaluates cytological changes and the cellular architectural arrangement of the lesions, determining them as having "mild epithelial dysplasia," "moderate epithelial dysplasia," and "severe epithelial dysplasia."16 Such model provides information on how much the lesion is prone to malignancy. 8,14,17

Nucleolar organizing regions are structures present in the nucleolus of the interphase cells and in the acrocentric

() The Author(s). 2020 Open Access This article is distributed under the terms of the Creative Commons Attribution 4.0 International License (https://creativecommons. org/licenses/by-nc/4.0/), which permits unrestricted use, distribution, and non-commercial reproduction in any medium, provided you give appropriate credit to the original author(s) and the source, provide a link to the Creative Commons license, and indicate if changes were made. The Creative Commons Public Domain Dedication waiver (http://creativecommons.org/publicdomain/zero/1.0/) applies to the data made available in this article, unless otherwise stated. 
chromosomes pairs 13, 14, 15, 21, and 22 during human cell division. ${ }^{18}$ Previous studies have applied the AgNOR method to cancerous lesions and malignant tumors, describing that this technique can be considered a marker for cell proliferation rate and can be used for prognostic purposes. . $^{12,19,20}$

Thus, the present study aimed to correlate the average number of NORs obtained in 100 epithelial cell nuclei of a series of oral leukoplakias with three methods of histopathological classification of such lesion, already recognized in the literature.

\section{Materials and Methods \\ Study Design and Data Collection}

The study was approved by the Research Ethics Committee of the University of Passo Fundo (Opinion No. 172/2011) under C. A. A. E. 0034.0.398.000-11. A cross-sectional laboratory histopathologicalhistochemical study was performed in a series of oral leukoplakia cases. The analyzed cases were filed at the Pathology Service of the SDH/ICB/UPF.

\section{Sample Selection}

All cases of leukoplakia diagnosed at SDH/ICB/UPF from 2017 to 2018 were selected. For this purpose, we used histopathological sections $(5 \mu \mathrm{m})$ of such cases from incisional or excisional oral biopsies performed by dentists from Passo Fundo/RS/Brazil region. The histopathological diagnoses were blindly reviewed and confirmed by an experienced oral pathologist and subsequently compared with the clinical information sent by the dentists. It resulted in a selection of 18 cases of oral leukoplakia.

\section{Inclusion Criteria}

The study included all cases histopathologically diagnosed as hyperparakeratosis, hyperorthokeratosis with or without acanthosis, with or without epithelial cell dysplasia; and cases that, in addition to the histopathological features described above, were clinically represented by keratotic white or gray spot or plaque. It was included in the sample only cases with acceptable diagnostic quality, intraoral or lip location, referred by dentists and with information on age, gender, and lesion location.

\section{Exclusion Criteria}

We excluded from the sample cases that had insufficient histopathological material for analysis and cases with incomplete or insufficient clinical information to reach the diagnosis of leukoplakia.

\section{Training and Examinations}

At this stage of the study, a single dentist (oral pathologist) received calibration training for diagnosis and classification of oral cancerous lesions compatible with leukoplakia. For this step, a set of training blades was applied to the lesions.

\section{Histopathological Classifications}

The data were retrospectively collected, since the cases already had a report. Thus, the histopathological diagnosis was confirmed and the histopathological classifications were assigned as follows. All analyzes were performed under the examiner's blinding, through photonic microscopy, with immersion objective $(1,000 \times)$. Methods were used for histopathological classification of lesions, following the literature. ${ }^{21,22}$
The WHO method codified the tissue samples into 1, 2, and 3, respectively: (1) "Mild dysplasia": increased number of cells in the basal and parabasal epithelial regions showing nuclear hyperchromatism and pleomorphism; (2) "Moderate dysplasia": bulbous straight processes with increased cell numbers showing nuclear hyperchromatism and pleomorphism, extending to and including basal, parabasal, and spinous layers; (3) "Severe dysplasia": bulbous straight processes with increased cell numbers showing nuclear hyperchromatism and pleomorphism throughout the epithelial thickness. ${ }^{23}$ In addition to the previously described classifications for the WHO method, the Brothwell system considered the "carcinoma in situ" level, characterized by epithelial alterations showing nuclear hyperchromatism and pleomorphism, which covers the entire thickness of the epithelium, suggesting an early superficial tissue invasion, but without convincing evidence. ${ }^{21}$

The binary system considered: "high risk" - with potential susceptibility to malignant transformation, resulting in at least four architectural alterations and five cytological alterations; and "low risk" - without susceptibility to malignant transformation, being associated with less than four architectural changes or less than five cytological changes. ${ }^{22}$

\section{Histochemical Analysis}

In addition to the hematoxylin-eosin-stained tissue samples that allowed the diagnosis and histopathological classification of leukoplakia, new tissue sections were obtained from each case ( 3 $\mu \mathrm{m}$ thick), to be impregnated by the AgNOR technique, described by Ploton et al., ${ }^{23}$ with some modifications:

This technique is described as follows: (1) $50 \mathrm{~mL}$ of Mili-Q water was added as an initial solution, adding $0.5 \mathrm{~mL}$ of formic acid and $1 \mathrm{~g}$ of gelatin. (2) The obtained solution was kept in an oven at $45^{\circ} \mathrm{C}$ for 1 hour incubation period. Then a second solution was produced with $10 \mathrm{~mL}$ of distilled water and $5 \mathrm{~g}$ of silver nitrate. (3) Thereby, both solutions were mixed and dripped onto the cell material disposed on the slide, thus remaining for 30 minutes in an oven at $45^{\circ} \mathrm{C}$. (4) Finally, a final wash was performed. (5) Such slides were analyzed under microscopy, and the nuclei of 100 epithelial cells were photographed to count the number of NORs per lesion.

\section{Statistical Analysis}

Epidemiological data regarding patients and their lesions were obtained from the histopathological reports of the cases for tabulation in Excel ${ }^{\mathrm{TM}}$ spreadsheet. They were later submitted to statistical analysis using SSPS software version 23.0 (Chicago, USA). The average number of NORs was compared with the three histopathological classifications through $t$ test or ANOVA means, with a significance level of $5 \%$ (Fig. 1).

\section{Results}

Of 18 analyzed lesions, $61.1 \%$ (11 cases) corresponded to males. The age of patients with oral leukoplakia ranged from 25 to 80 years, with a higher frequency between 46 years and 60 years (44.4\%) (mean age 53.22 years). Regarding ethnicity, there was a predominance of Caucasians (11 cases, 61.1\%), followed by melanoderms ( 5 cases, $27.8 \%$ ) and faiodermas ( 2 cases, $11.1 \%$ ).

Figure $2 \mathrm{~A}$ describes the information regarding the possible etiological factors of leukoplakias collected in histopathological reports. Table 1 reports additional data regarding cases of oral leukoplakia. Figure 2B represents the average number of NORs 


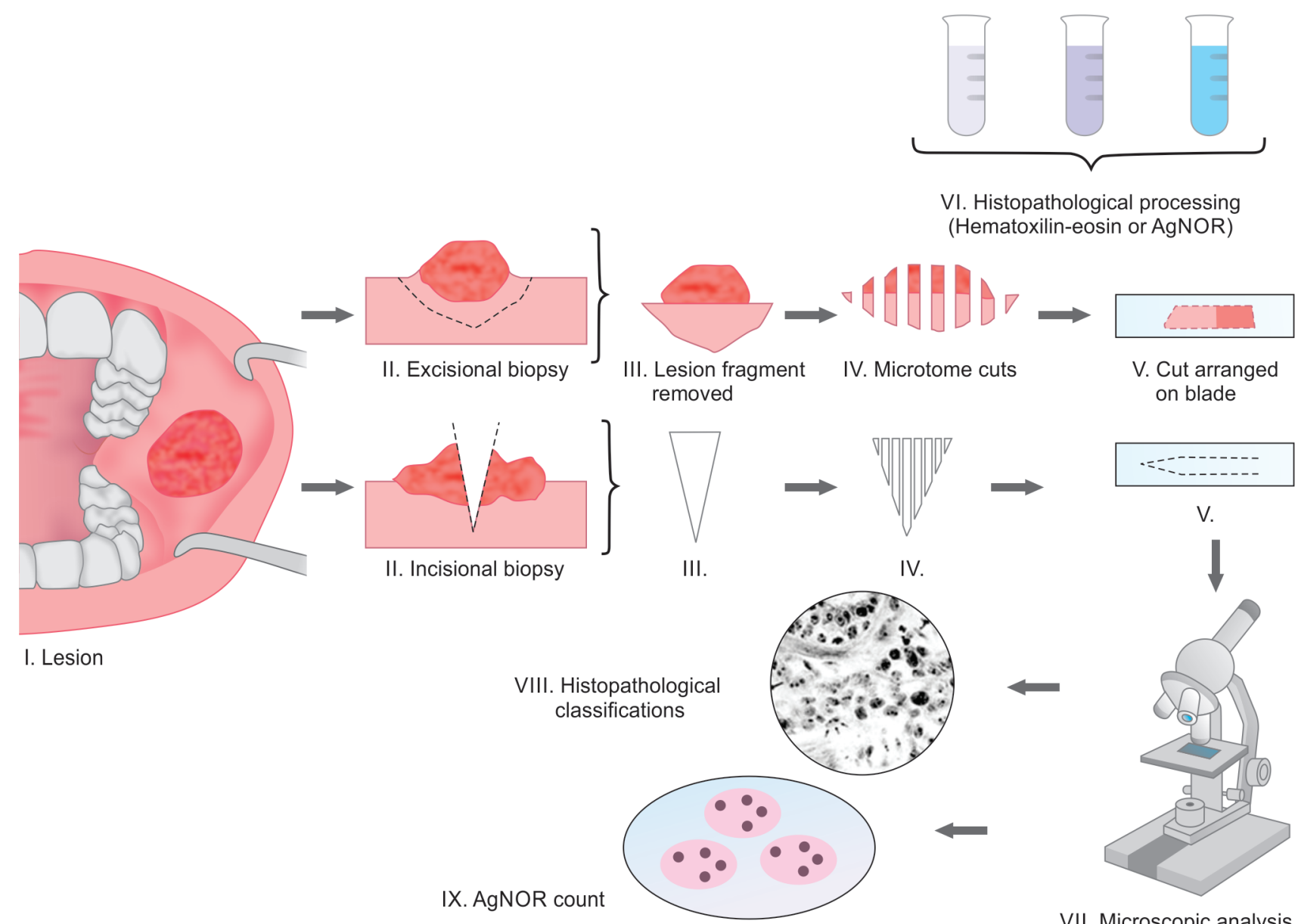

Fig. 1: Study's experimental flow diagram
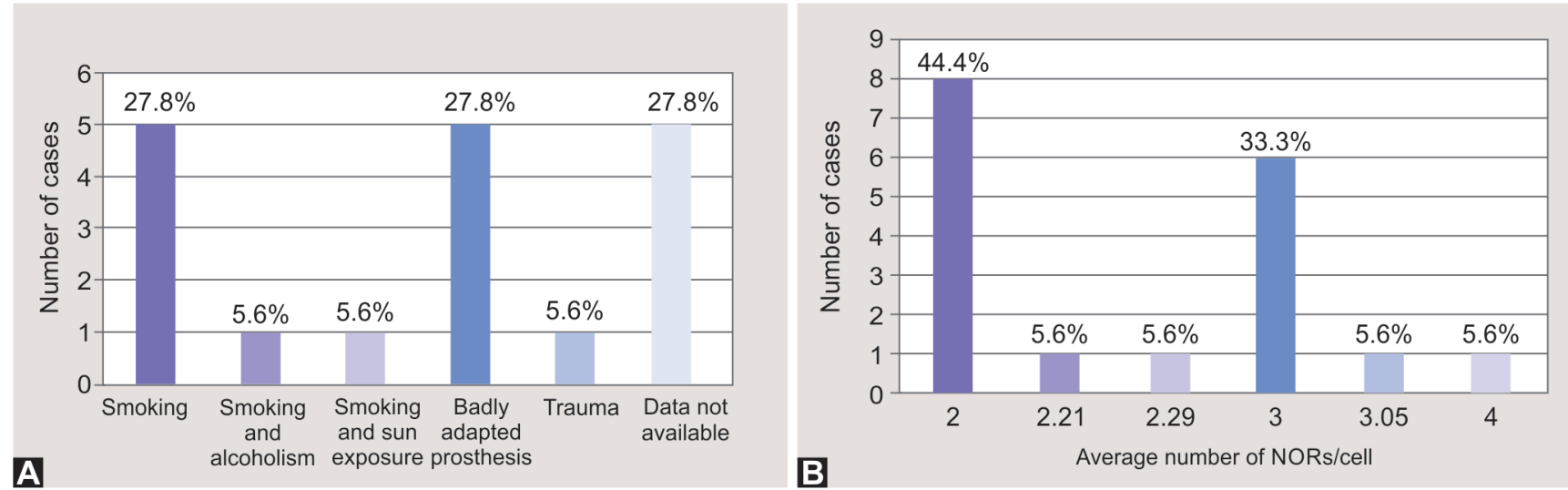

Figs 2A and B: (A) Distribution of oral leukoplakia cases according to etiological factors; (B) Distribution of NOR average observed in oral leukoplakia lesions

obtained from 100 epithelial cell nuclei from each of the 18 lesions analyzed.

All the three histopathological classification systems for leukoplakia (WHO, binary system, and Brothwell's) were compared with AgNOR results. Correlating the average number of NORs evaluated in 100 leukoplastic epithelial cell nuclei with the methods of histopathological classification of such lesions proposed by the $\mathrm{WHO}$ and the binary system, a statistical $t$ test (significance level of $5 \%$ ) was used. No statistically significant relationship was noted ( $p=0.190$ and $p=0.542$, respectively) (Tables 2A and B). When the mean number of leukoplakia NORs was related to Brothwell's histological classification, using the ANOVA test means, there was no statistically significant difference $(p=0.203)$ (Table 2C). 
Table 1: Absolute and percentage distribution of leukoplakia cases according to clinical features and methods of histopathological classification

\begin{tabular}{|c|c|c|}
\hline Feature & Incidence & Percentage \\
\hline \multicolumn{3}{|l|}{ Location } \\
\hline Lip & 1 & 5.6 \\
\hline Tongue & 2 & 11.1 \\
\hline Cheek mucosa & 6 & 33.3 \\
\hline Cheek mucosa and alveolar ridge & 1 & 5.6 \\
\hline Hard and soft palate & 1 & 5.6 \\
\hline Alveolar ridge & 2 & 11.1 \\
\hline Alveolar ridge and retromolar area & 3 & 16.7 \\
\hline Alveolar ridge and hard palate & 1 & 5.6 \\
\hline Data not available & 1 & 5.6 \\
\hline \multicolumn{3}{|l|}{ Symptomatology } \\
\hline Absent & 6 & 33.3 \\
\hline Present & 5 & 27.8 \\
\hline Present with burning & 3 & 16.7 \\
\hline Data not available & 4 & 22.2 \\
\hline \multicolumn{3}{|l|}{ Fundamental lesion } \\
\hline Spot & 1 & 5.6 \\
\hline Board & 16 & 88.9 \\
\hline Data not available & 1 & 5.6 \\
\hline \multicolumn{3}{|l|}{ Evolution time } \\
\hline $0.5-12$ months & 6 & 33.3 \\
\hline 13-24 months & 2 & 11.1 \\
\hline $25-36$ months & 6 & 33.3 \\
\hline Data not available & 4 & 22.2 \\
\hline \multicolumn{3}{|l|}{ Size } \\
\hline$\geq 20 \mathrm{~mm}$ & 10 & 55.6 \\
\hline$\leq 20 \mathrm{~mm}$ & 4 & 22.2 \\
\hline Data not available & 4 & 22.2 \\
\hline \multicolumn{3}{|l|}{ Consistency } \\
\hline Firm & 8 & 44.4 \\
\hline Firm and elastic & 1 & 5.6 \\
\hline Soft & 3 & 16.7 \\
\hline Soft and firm & 3 & 16.7 \\
\hline Data not available & 3 & 16.7 \\
\hline \multicolumn{3}{|l|}{ Borders } \\
\hline Defined & 5 & 27.8 \\
\hline Undefined & 6 & 33.3 \\
\hline Data not available & 7 & 38.9 \\
\hline \multicolumn{3}{|l|}{ Surface } \\
\hline Flat & 5 & 27.8 \\
\hline Flat and ulcerated & 4 & 22.2 \\
\hline Rough & 4 & 22.2 \\
\hline Rough and ulcerated & 1 & 5.6 \\
\hline Data not available & 4 & 22.2 \\
\hline \multicolumn{3}{|l|}{ Coloring } \\
\hline White (clear) & 9 & 50.0 \\
\hline Reddish white & 6 & 33.3 \\
\hline Black (blackened) & 2 & 11.1 \\
\hline Data not available & 1 & 5.6 \\
\hline
\end{tabular}

\begin{tabular}{lcc} 
Contd... & & \\
\hline Feature & Incidence & Percentage \\
\hline Method: WHO & 7 & 38.9 \\
$\quad$ Mild epithelial dysplasia & 11 & 61.1 \\
$\quad$ Moderate epithelial dysplasia & & \\
Method: Brothwell & 7 & 38.9 \\
$\quad$ Mild epithelial dysplasia & 9 & 50.0 \\
$\quad$ Moderate epithelial dysplasia & 1 & 5.6 \\
$\quad$ Severe epithelial dysplasia & 1 & 5.6 \\
$\quad$ Carcinoma in situ & & \\
Method: binary system & 8 & 44.4 \\
$\quad$ High risk & 10 & 55.6 \\
$\quad$ Low risk & 18 & 100 \\
Total &
\end{tabular}

\section{Discussion}

In order to validate the AgNOR method as a determinant tool for oral leukoplakia prognosis, the present study has correlated the average number of NORs with data related to histopathological classifications of leukoplakias.

Several classification systems of epithelial dysplasias have been created. An example is the degree of dysplasias idealized by Brothwell et al., ${ }^{21}$ which consists in a point-scale classification system. Such system determines lesions as "mild," "moderate," "severe," and "carcinoma in situ."16 This form of classification is very similar to the WHO one, which considers epithelial changes at the architectural level and classifies them based on epithelial stratification. The binary classification system gathers lesions into fewer categories, classifying them only as "high risk" and "low risk" lesions. $^{16,22}$

Biological markers have been used to determine the behavior of lesions, which should be able to provide information about the biological characteristics involved in cell proliferation or neoplastic cell transformation. ${ }^{18-20}$ One of these markers is the histochemical technique of silver tissue impregnation AgNORs. ${ }^{19}$ This technique detects proteins associated with the transcriptional activity of NORs through colloidal silver impregnation, named AgNOR proteins. In this technique, NORs can be visualized under photonic microscopy as small, well-defined dark spots within the cell nucleus. ${ }^{19,21}$

According to the carried out studies, a high prevalence of leukoplakias was observed in men, which is consistent with the results of the present study, since lesions in men represented $61.1 \%$ of the sample. ${ }^{12,24}$ Hallikeri et al. ${ }^{11}$ observed that $98.78 \%$ of the leukoplakia cases they have studied occurred in smokers, whereas in our study, smokers represented only $39.0 \%$. According to Lee et al., ${ }^{24}$ the most frequent anatomical location of leukoplakias was the cheek mucosa, which matches with the present study, where such anatomical site represented $33.3 \%$ of the cases. Regarding the age of patients, there was a higher prevalence of leukoplakias between the fourth and sixth decades of life. This finding coincides with the statement that oral leukoplakia is most commonly found in individuals over 50 years old. ${ }^{10,25}$

NORs count is used as a biological marker to estimate the degree of cell proliferation. ${ }^{19}$ In this sense, Madan et al. ${ }^{26}$ demonstrated the difference in the average number of AgNORs between nondysplastic epithelium and oral squamous cell carcinoma. In another study, the AgNOR count technique helped distinguishing cancerizable lesions and oral squamous cell carcinomas. ${ }^{19}$ 
Oral Leukoplakia and its Cell Proliferative Activity

Tables 2A to C: Statistical crossovers between histopathological classification method proposed by (A) WHO, (B) binary system, (C) Brothwell's histopathological classification method, and average number of NORs

\begin{tabular}{|c|c|c|c|c|c|}
\hline (A) & WHO method & $n$ & Mean & Standard deviation & Standard error \\
\hline \multirow[t]{2}{*}{ NORs average in 100 nuclei } & Mild epithelial dysplasia & 7 & 2.2929 & 0.50036 & 0.18912 \\
\hline & Moderate epithelial dysplasia & 11 & 2.6818 & 0.63361 & 0.19104 \\
\hline \multicolumn{6}{|l|}{$p$ value $=0.190$ ( $t$ test $)$} \\
\hline (B) & Binary system & $n$ & Mean & Standard deviation & Standard error \\
\hline \multirow[t]{2}{*}{ NOR average in 100 nuclei } & High risk & 8 & 2.6313 & 0.52300 & 0.18491 \\
\hline & Low risk & 10 & 2.4500 & 0.67521 & 0.21352 \\
\hline \multicolumn{6}{|l|}{$p$ value $=0.542$ ( $t$ test $)$} \\
\hline (C) & Brothwell's classification & $n$ & Mean & Standard deviation & Standard error \\
\hline \multirow[t]{5}{*}{ NOR mean/100 nuclei } & Mild dysplasia & 7 & 2.8871 & 0.64999 & 0.24567 \\
\hline & Moderate dysplasia & 9 & 2.3711 & 0.49334 & 0.16445 \\
\hline & Severe dysplasia & 1 & 2.0000 & & \\
\hline & Carcinoma in situ & 1 & 2.0000 & & \\
\hline & Total & 18 & 2.5306 & 0.60215 & 0.14193 \\
\hline$p$ value $=0.203($ ANOVA $)$ & & & & & \\
\hline
\end{tabular}

In addition, previous research results suggest that the average of AgNORs may be proportional to the epithelial cell proliferative activity. ${ }^{19}$ Furthermore, studies suggest that with the malignancy of the lesion, the number of AgNORs tends to increase. ${ }^{27}$ Thus, it is hypothesized that the number of NORs of oral leukoplakias would be directly proportional to the increase in their histopathological grading.

Sowmya et al. ${ }^{28}$ investigated, through the AgNOR method in exfoliative cytologies, the cell proliferative activity of healthy patients with oral leukoplakia, oral submucosal fibrosis, and squamous cell carcinoma. These authors concluded that AgNOR is a simple, sensitive, and inexpensive method for differentiating premalignant from malignant lesions and can be used in conjunction with routine cytomorphological evaluation.

However, in the present study, no statistically significant relationship was observed between the average number of NORs and the histopathological classification methods, i.e., the grading increase of three histological classifications studied was not related to a higher average number of NORs per cell nucleus. The fact that in the present study most of the cases analyzed presented mild or moderate epithelial dysplasia may explain why the NOR count was not useful in differentiating the histological grades of leukoplakias, since the literature states that such technique is more effective in lesions with severe dysplasia. ${ }^{19,29}$

Spolidorio et al. ${ }^{30}$ also reported that there were no statistically significant differences in AgNOR count between lesions with different histological grades, only pointing to a morphology and distribution patterns of NORs within cell nuclei distinctions.

The findings of the present study are also supported by results of Carmo and Silva, ${ }^{31}$ who studied 22 cases of ameloblastoma and 10 cases of adenomatoid odontogenic tumor using the AgNOR method and they found out that the clinical behavior of such lesions is not related to their proliferation index, although the origin of such lesions is different from the origin of leukoplakias.

Madan et al. ${ }^{26}$ evaluated the cell proliferative activity (AgNOR method) of 30 leukoplakia cases ( 15 cases with dysplasia and 15 with no dysplasia), 15 cases of squamous cell carcinoma, and 5 cases of normal oral mucosa. The authors found that the NOR count in carcinomas was lower than in dysplastic lesions. In addition, the mean NOR count was not statistically different between dysplastic and non-dysplastic leukoplakias. Thus, these authors conclude that the average of NORs cannot, as an isolated factor, serve to distinguish normal epithelium from cancerous lesions or oral carcinomas.

Khushbu et al. ${ }^{32}$ aimed to investigate the rate of cell proliferation and biological aggressiveness of normal epithelium, cancerous lesions (leukoplakias), and malignant lesions (squamous cell carcinomas) using the AgNOR method. However, they found that the amount of NORs does not necessarily indicate tissue malignancy.

Thus, in the present study, the amount of NORs was not significantly related to three established histopathological classifications for oral leukoplakia. Thereby, the AgNOR method should be used with caution when differentiating leukoplakias of different histological grades or when distinguishing between cancerizable oral lesions and malignant lesions.

It is important to note that the present study has limitations regarding the sample, once it consists in only 18 lesions and the fact that the patients were not clinically followed up in order to determine the actual prognosis of the analyzed cases.

\section{Conclusion}

From the studied sample and applied methodology in the present investigation, it can be inferred that the average number of NORs is not associated with the recognized histopathological classifications for oral leukoplakias.

\section{Clinical Significance}

The AgNOR method should be used with caution to determine the clinical treatment of oral leukoplakias, since no agreement was observed between this method and the histopathological classifications available for such lesion.

\section{ACKnOWLedgment}

The authors would like to thank the Department of Pathology of University of Passo Fundo, RS, Brazil, for its support to the present study. 


\section{References}

1. Van Der Waal I. Potentially malignant disorders of the oral and oropharyngeal mucosa; terminology, classification and present concepts of management. Oral Oncol 2009;45(5):317-323. DOI: 10.1016/j.oraloncology.2008.05.016.

2. Rhodus NL, Kerr AR, Patel K. Oral câncer: lukoplakia, premalignancy and squamous cell carcinoma. Dent Clin North Am 2014;58(2): 315-340. DOI: 10.1016/j.cden.2013.12.004.

3. Queiroz SIML, Medeiros AMC, Silva JSP, et al. Clinical and histopathological evaluation and habits associated with the onset of oral leukoplakia and erythroplakia. J Bras Patol Med Lab 2014;50(2):144-149. DOI: 10.5935/1676-2444.20140008.

4. Carreras-Torras C, Gay-Escoda C. Techniques for early diagnosis of oral squamous cell carcinoma: systematic review. Med Oral Patol Oral Cir Bucal 2015;20(3):305-315. DOI: 10.4317/medoral.20347.

5. El-Naggar AK, Chan J, Takata T, et al. WHO classification of tumours. Pathology and Genetics of Head and Neck Tumors. 4th ed., Lyon, France: IARC Press; 2017.

6. Warnakulasuriya $S$. Clinical features and presentation of oral potentially malignant disorders. Oral Surg Oral Med Oral Pathol Oral Radiol 2018;125(6):582-590. DOI: 10.1016/j.00oo.2018.03.011.

7. Starzyńska A, Pawłowska A, Renkielska D, et al. Estimation of oral leukoplakia treatment records in the research of the Department of Maxillofacial and Oral Surgery, Medical University of Gdansk. Postepy Dermatol Alergol 2015;32(2):114-122. DOI: 10.5114/pdia.2014. 40791.

8. Ranganathan K, Kavitha L. Oral epitelial dysplasia: classifications and clinical relevance in risk assessment of oral potentially malignant disorders. J Oral Maxillofac Pathol 2019;23(1):19-27. DOI: 10.4103/ jomfp.JOMFP_13_19.

9. Yang YH, Ho PS, Lu HM, et al. Comparing doseresponse measurements of oral habits on oral leukoplakia and oral submucous fibrosis from a community screening program. J Oral Pathol Med 2010;39(4): 306-312. DOI: 10.1111/j.1600-0714.2009.00820.x.

10. Mendez M, Carrard VC, Haas AN, et al. A 10-year study of specimens submitted to oral pathology laboratory analysis: lesion occurrence and demographic features. Braz Oral Res 2012;26(3):235-241. DOI: 10.1590/S1806-83242012000300009.

11. Hallikeri K, Naikmasur V, Guttal K, et al. Prevalence of oral mucosal lesions among smokeless tobacco usage: a cross-sectional study. Indian J Cancer 2018;55(4):404-409. DOI: 10.4103/ijc.IJC_178_18.

12. Mello FW, Miguel AFP, Dutra KL, et al. Prevalence of oral potentially malignant disorders: a systematic review and meta-analysis. J Oral Pathol Med 2018;47(7):633-640. DOI: 10.1111/jop.12726.

13. Narayan TV, Shilpashree S. Meta-analysis on clinicopathologic risk factors of leukoplakias undergoing malignant transformation. J Oral Maxillofac Pathol 2016;20(3):354-361. DOI: 10.4103/0973029X.190900.

14. Cho KJ, Song JS. Recent changes of classification for squamous intraepithelial lesions of the head and neck. Arch Pathol Lab Med 2018;142(7):829-832. DOI: 10.5858/arpa.2017-0438-RA.

15. Baykul T, Yilmaz H, Aydin Ü, et al. Early diagnosis of oral cancer. J Int Med Res 2010;38(3):737-749. DOI: 10.1177/147323001003800302.

16. Gale N, Blagus R, El-Mofty SK, et al. Evaluation of a new grading system fot laryngeal squamous intraepithelial lesions- a proposed unified classification. Histopathology 2014;65(4):456-464. DOI: 10.1111/ his.12427.
17. Abdalla Z, Walsh T, Thakker N, et al. Loss of epithelial markers is an early event in oral dysplasia and is observed within the safety margin of dysplastic and T1 OSCC biopsies. PLoS ONE 2017;12(12):e0187449. DOI: 10.1371/journal.pone.0187449.

18. Geetha KM, LeeKy M, Narayan TV, et al. Grading of oral epitelial dysplasia: Points to ponder. J Oral Maxillofac Pathol 2015;19(2):198204. DOI: 10.4103/0973-029X.164533.

19. Tomazelli KB, Modolo F, Rivero ER. Evaluation of AgNORs in oral potentially malignant lesions. J Oncol 2015. 218280. DOI: 10.1155/2015/218280.

20. Nikitakis NG, Pentenero M, Georgaki M, et al. Molecular markers associated with development and progression of potentially premalignant oral epitelial lesions: current knowledge future implications. Oral Surg Oal Med Oral Pathol Oral Radiol 2018;125(6):650-669. DOI: 10.1016/j.00oo.2018.03.012.

21. Brothwell DJ, Lewis DW, Bradley G, et al. Observer agreement in the grading of oral epithelial dysplasia. Community Dent Oral Epidemiol 2003;31(4):300-305. DOI: 10.1034/j.1600-0528.2003.00013.x.

22. Kujan O, Oliver RJ, Khattab A, et al. Evaluation of a new binary system of grading oral epithelial dysplasia for prediction of malignant transformation. Oral Oncol 2006;42(10):987-993. DOI: 10.1016/j. oraloncology.2005.12.014.

23. Ploton $D$, Menager $M$, Jeannesson $P$, et al. Improvement in the staining and in the visualization of the argyrophilic proteins of the nucleolar organizer region at the optical level. J Histochemical 1986;18(1):5-14. DOI: 10.1007/bf01676192.

24. Lee JJ, Hung HC, Cheng SJ, et al. Carcinoma and dysplasia in oral leukoplakias in Taiwan: prevalence and risk factors. Oral Surg, Oral Med, Oral Pathol, Oral Radiol, Endod 2006;101(4):472-480. DOI: 10.1016/j.tripleo.2005.07.024.

25. Ferreira A, Souza EEL, Oliveira TC, et al. Prevalence and factors associated with oral potentially malignant disorders in Brazil's rural workres. Oral Dis 2016;22(6):536-542. DOI: 10.1111/odi.12488.

26. Madan M, Chandra S, Raj V, et al. Evaluation of cell proliferation in malignant and potentially malignant oral lesions. J Oral Maxillofac Pathol 2015;19(3):297-305. DOI: 10.4103/0973-029X.174613.

27. Chowdhry A, Deshmukh RS, Shukla D, et al. Quantitative estimation of AgNORs in normal, dysplastic and malignant oral mucosa. Biomed Pap Med Fac Univ Palacky Olomouc Czech Repub 2014;158(2): 282-287. DOI: 10.5507/bp.2013.002.

28. Sowmya G, Nahar P, Astekar M, et al. Analysis of silver binding nucleolar organizer regions in exfoliative cytology smears of potentially malignant and malignant oral lesions. Biotech Histochem 2017;92(2):115-121. DOI: 10.1080/10520295.2017.

29. Manchanda A, Shetty DC. Reproducibility of grading systems in oral epithelial dysplasia. Med Oral Patol Oral Cir Bucal 2012;17(6): e935-e942. DOI: 10.4317/medoral.17749.

30. Spolidorio LC, Neves KA, Soares CP, et al. Evaluation of argyrophilic nucleolar organizer regions in oral tumor progression. Micron 2002;33(7-8):605-608. DOI: 10.1016/s0968-4328(02)00031-8.

31. Carmo MA, Silva EC. Argyrophilic nucleolar organizer regions (AgNORs) in ameloblastomas and adenomatoid odontogenic tumours (AOTs). J Oral Pathol Med 1998;27(4):153-156. DOI: 10.1111/ j.1600-0714.1998.tb01932.x.

32. Khushbu B, Chalishazar M, Kale H, et al. Quantitative and qualitative assessment of argyrophilic nucleolar organizer regions in normal, premalignant and malignant oral lesions. J Oral Maxillofac Pathol 2017;21(3):360-366. DOI: 10.4103/jomfp.JOMFP_52_15. 